\title{
Development of a New Algorithm to Address the Transportation Issue
}

\author{
A. N. M. Rezaul Karim ${ }^{1, *}$, Farzana Sultana Rafi ${ }^{2}$, Mohammed Nizam Uddin ${ }^{2}$, Md. Iftakhar Mahmud ${ }^{2}$, \\ Mayeen Uddin Khandaker ${ }^{3}$, Riaz Mahmud ${ }^{4}$, M. R. I. Faruque ${ }^{5}$
${ }^{1}$ Department of Computer Science \& Engineering, International Islamic University Chittagong, Bangladesh ${ }^{2}$ Department of Applied Mathematics, Noakhali Science and Technology University, Bangladesh Sunway, Selangor, Malaysia
${ }^{4}$ Department of Mathematics, Faculty of Mathematics and Computer Science, South Asian University, New Delhi 110021, India
${ }^{5}$ Space Science Centre (ANGKASA), Universiti Kebangsaan Malaysia, 43600 UKM, Bangi, Selangor, Malaysia \\ ${ }^{3}$ Centre for Applied Physics and Radiation Technologies, School of Engineering and Technology, Sunway University, 47500 Bandar
}

Received May 19, 2021; Revised July 14, 2021; Accepted September 18, 2021

\section{Cite This Paper in the following Citation Styles}

(a): A. N. M. Rezaul Karim, Farzana Sultana Rafi, Mohammed Nizam Uddin, Md. Iftakhar Mahmud, Mayeen Uddin Khandaker, Riaz Mahmud, M. R. I. Faruque , "Development of a New Algorithm to Address the Transportation Issue," Civil Engineering and Architecture, Vol. 9, No. 6, pp. 2105-2116, 2021. DOI: 10.13189/cea.2021.090638.

(b): A. N. M. Rezaul Karim, Farzana Sultana Rafi, Mohammed Nizam Uddin, Md. Iftakhar Mahmud, Mayeen Uddin Khandaker, Riaz Mahmud, M. R. I. Faruque (2021). Development of a New Algorithm to Address the Transportation Issue.Civil Engineering and Architecture, 9(6), 2105-2116. DOI: 10.13189/cea.2021.090638.

Copyright $\mathrm{C} 2021$ by authors, all rights reserved. Authors agree that this article remains permanently open access under the terms of the Creative Commons Attribution License 4.0 International License

\begin{abstract}
Transportation issues are particularly important when it comes to delivering products to customers at a reasonable cost and promptly. Even though most real-world transportation problems have many challenges, these issues cannot be solved using conventional approaches. The literature contains several strategies for obtaining a feasible solution to the transportation problem, including the most effective Vogel's approximation technique (VAM). Other methods available in the literature are Least Cost Method, NWC Method, Column Minima Method, and Row Minima Method. However, existing methods do not always provide a good effective solution that can reduce the number of iterations to find the best solution. Thus, the development of improved approaches to transportation problems is still challenging. The proposed method is based on a very simple, easy-to-understand, and realistic for transportation issues. Methods: In this analysis, a more efficient, simple, and quick computation methodology has been established. This approach was coded using the PyCharm 3.1 programming platform and the Python 3.8 programming language. Results and Conclusion: The proposed strategy has been demonstrated with numerical examples. A collection of benchmark cases is used to evaluate the new process. This was compared with other conventional
\end{abstract}

methods, the test results indicating that the proposed method has the lowest cost compared to others and has reached a faster solution time, optimal solution and it outperforms the VAM and other commonly used approaches. As a result, our new method can be thought of as a distinct approach to finding the quickest solution to any transportation problem. Keywords Transportation Problem, Linear
Programming, Vogel's Approximation Method

\section{Introduction}

Transportation problem (TP) is a special class of network optimization [1] problem that deals with the delivery of products from some viewpoints [2]. Factory owners who can meet the needs of customers on time are at the forefront of market rivalry, so a viable transportation solution becomes a critical issue. In fact, the price of a product largely depends on the way of convenience for transporting/sending it to the consumer. Particularly, a reduction in transportation costs eventually brings a great benefit for both the seller and the 
buyer/consumer. The network optimization in TP helps to determine the minimum total cost for transporting a single product from a set of sources to a set of destinations. It has been widely studied in the area of information discipline and facilities administration, in which the allotment of materials and items from source to destination is a significant problem [3]. This issue has been referred to as a shipping concern as much of its uses include deciding whether to move materials optimally [4]. The common criteria of the transport issue are capital, places, and methods of travel [5]. Since transport models play a significant role in the distribution of products and services, it was studied for several centuries, and still, it shows the importance of finding a cost-effective process in this modern and busy world. Several convenient methods/models that show suitable in solving transportation problems in various circumstances are identified as Northwest Corner Method, Least Cost Method, Vogel's Approximation Method [6], Row Minima Method, and Column Minima Method [7]. In all of these methods, the associated algorithms are designed to conform to the destination requirements [8].

In general, all approaches or models available in the literature were developed using the key steps or procedures listed below:

Phase 1: Modes of action in mathematics.

Phase 2: Considering an original simple answer that is feasible.

Phase 3: Optimizing the original workable, simple approach [2].

This article introduces a new algorithm to obtain a rapid way to solve transportation problems that are quick to learn and easy to implement. The main objective of this proposed method is to find a way to solve the transportation problem which will be very easy and rapid time consuming, with a better optimal result.

\section{Literature Review}

The primary goal of the transportation issue is to supply goods following the demand of the consumer at a low cost and relatively short time. After the product is manufactured in certain factories, it is transported to specified clients in various parts of the country. Transportation issues are defined as cost-effective, timely, and quick delivery options that fulfil client demand. In this scenario, the fewer the factories/sources and the fewer the customers, the easier it is to find a solution. However, for a greater number of sources and consumers, the solution is not very straightforward, thus needs to be developed following complex mathematical programming or process. Many methods or models are available in the literature to solve the cost-and-time-minimization issues in the transportation problem.
The transportation model was first officially established in 1781 by a French mathematician, Gaspard Mong. Nevertheless, the fundamental transport concern was initially introduced by Hitchcock in 1941[2]. Later, realizing the transportation problem in World War II, Leonid Kantorovich introduced the most important approach in this regard [9]. In connection to this, many researchers played a noteworthy role to develop novel thoughts and techniques to resolve various characteristics of the transportation problem [10]. Nevertheless, according to many recent studies, Vogel's Approximation Method (VAM) shows outperformance compared with other existing methods. For instance, Das et al. reported that Vogel's scheme is known to be the strongest tool of all current systems [11]. Although Vogel's method is good for solving transportation problems, it has some limitations such as it requires a long mathematical calculations step which is quite complicated and time-consuming.

As a result, several researchers have attempted to improve Vogel's Approximation Method (VAM). Ezekiel modified VAM to obtain a systematic and transparent solution which gives a better result for the more scientific transportation problem. In that study, the author worked with three sources and four destinations for Dangote Cement Factory in Nigeria [12]. In the case of unbalanced TP, the solution obtained by VAM may not be effective, because VAM allocates terms to the dummy cells before the other cells present in the transportation table. Shimshak et al. worked with this drawback of VAM and modified the VAM to ignore any penalty that involves any dummy row or column [13]. Abdul Sattar et al. tweaked Vogel's method to find the better optimal result and found that the result of the modified method and Vogel's method was almost the same optimal but better than the North West Corner Method and Least Cost Method [14]. Samuel and Venkatachalapathy worked on the development of VAM for fuzzy transportation problems and obtained a method that was simple to comprehend and superior to previous methods [15]. Dey et al. modified Classical VAM to solve the fuzzy transportation problem which is effective to apply in the real world. In their study, type 2 Fuzzy wet was used because the complexity is too much for the fuzzy set 1 to manage human thought. The authors proposed an algorithm considering trapezoidal costs interval for solving fuzzy transportation problems which were exemplified by two small-scale problems [16]. Akpan et al. modified Vogel's Method to reduce total cost and compare the modification with other existing methods which proved that the modified method gave a better result than others except for Vogel's method. Their modified and Vogel's methods gave the same optimal result $[17,18]$. Mesbahuddin et al. proposed a method named the allocation table method, which gave most of the time the same optimal result and sometimes gave better results compared to the VAM [2].In recent years, 
some researchers have also worked to refine the other existing methods including Vogel's scheme, for example, Mishra et al. Modified the Northwest Corner Method [19].

Although several researchers attempted to improve on Vogel's Method to obtain a better outcome, none of the modified approaches produced a better outcome than Vogel's Method. Some of the proposed/modified methods produce better results than the VAM in a few circumstances, but they produce the same outcomes as the VAM in the vast majority of cases. Even though much research has been done on Vogel's modified approaches, there are ways to bridge the gap through additional studies.

In this regard, we developed a new approach that is more powerful than Vogel's Method by removing the disadvantages of existing methods using advanced programming languages. The newly proposed approach can be used to minimize total transportation costs while still meeting supply and demand constraints and meeting target requirements in terms of source specifications.

\section{Theoretical Concept of a Particular TP}

The network structure of the transportation problem is given in Figure 1 where the oval shape represents the production or source of the desired product and the rectangle shape represents the destination of the demand. Generally, the capacity of sources (m) and the demand of customers (n) is known. The target of the transportation problem is to carry the desired units of demandable products from the production house to the destination place within a rapid time or less cost.
Table 1 shows how to represent the transportation problem numerically. Here, $c_{i j}$ is the cost of transporting a unit of product from $\mathrm{i}^{\text {th }}$ source to $\mathrm{j}^{\text {th }}$ destination, $x_{i j}$ is the quantity of the desired product from $i^{\text {th }}$ - source to $\mathrm{j}^{\text {th }}$-destination, $\mathrm{a}_{\mathrm{i}}$ is the available collection of desired products in the production house, and $b_{j}$ is the quantity of demand of the customer at the destinations.

Table 1. Tabular representation of the transportation problem

\begin{tabular}{|c|c|c|c|c|c|}
\hline $\begin{array}{c}\text { Destination } \\
\text { Source }\end{array}$ & $\boldsymbol{t}_{\mathbf{1}}$ & $\boldsymbol{t}_{\mathbf{2}}$ & -- & $\boldsymbol{t}_{\boldsymbol{n}}$ & $\operatorname{Supply}\left(\boldsymbol{a}_{\boldsymbol{i}}\right)$ \\
\hline$p_{1}$ & $c_{11}$ & $c_{12}$ &.. & $c_{1 n}$ & $a_{1}$ \\
\hline$p_{2}$ & $c_{21}$ & $c_{22}$ & $\ldots$ & $c_{2 n}$ & $a_{2}$ \\
\hline----- & ---- & ----- & --- & ----- & ------ \\
\hline$p_{m}$ & $c_{m 1}$ & $c_{m 2}$ & -- & $c_{m n}$ & $a_{m}$ \\
\hline $\begin{array}{c}\text { Demand } \\
\left(b_{j}\right)\end{array}$ & $b_{1}$ & $b_{2}$ & $\ldots$ & $b_{n}$ & $\sum a_{i}=\sum b_{j}$ \\
\hline
\end{tabular}

If the supply and demand of the product is equal $\left(\sum a_{i}=\sum b_{j}\right)$; if so, it is referred to as a balanced transportation problem; otherwise, it is referred to as an unbalanced transportation problem. An unbalanced transportation problem can be easily solved by taking a dummy column or row. Mathematically, the transportation problem is a linear programming problem in which the objective function has to minimize the shipping cost with demand and supply constraints.

$$
\text { Minimize } z=\sum_{i}^{m} \sum_{j}^{n} c_{i j} x_{i j}
$$

Subject to the constraints,

$$
\begin{gathered}
\sum_{j}^{n} x_{i j}=a_{i}, i=1,2, \ldots, m \text { (supplyconstraints) } \\
\sum_{i}^{m} x_{i j}=b_{j}, j=1,2, \ldots, n \text { (demandconstraints) } \\
x_{i j} \geq 0 \text { for all } \mathrm{i} \text { and } \mathrm{j}
\end{gathered}
$$

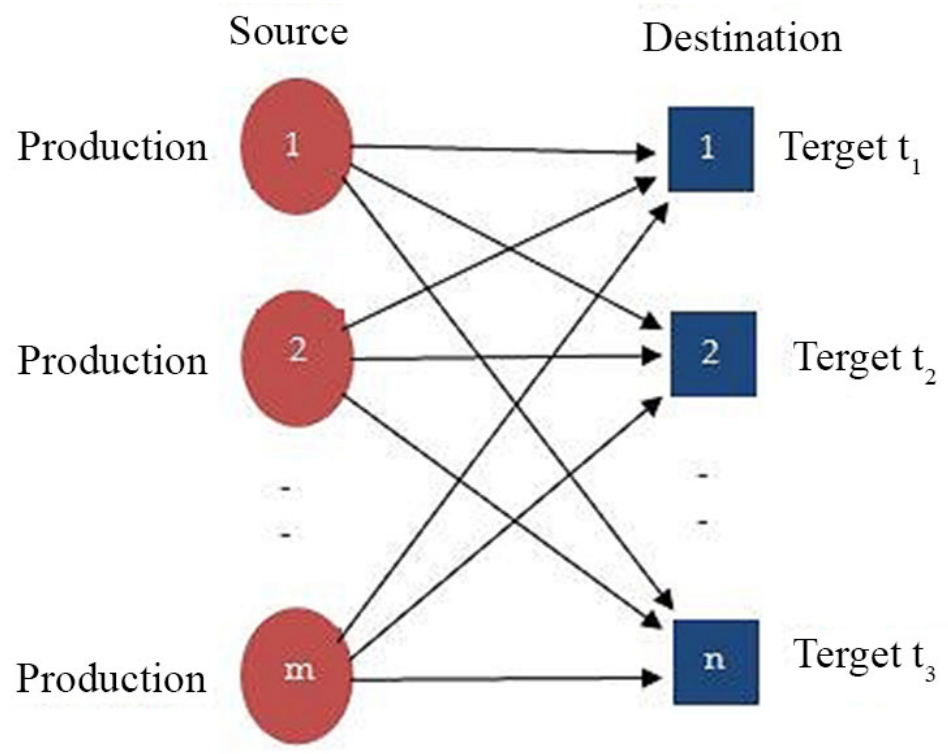

Figure 1. Networking diagram of the transportation problem 


\section{Proposed Method}

Following the typical three-phase steps for the solution of the transportation problem, we have designed a six-phase concept to solve the TP more conveniently. The proposed steps follow a sequential process, and a related programming structure or algorithm has been developed (See in Table $2 \& 3$ ).

The key difference between our approach and the existing literature is that it was built using the most up-to-date computational scheme, which makes the calculations very simple.

\subsection{Workflow of the ProposedMethod}

The phases of the alternate approach suggested are listed below:

Phase 1: Choose the minimum two costs from every column and row in the TP Table.

Phase 2: Evaluate the mean worth.

Phase 3: Investigate a column or row representing the lowest mean worth. When one or two is the lowest cost tie and then picks a row or column with the lowest cost-benefit.

Phase 4: Investigate the smallest expense of the column or row picked at Phase 3. When two or further of the identical minimum expenditure are associated, in that case, pick the expense that correlates to the nearly suitable portion. When two or more expenditures show the same type of allocation; then select an arbitrary unit.

Phase 5: Allocate the desired interest to the expense selected in Phase 4. When the requirement is met, highlight the related column, if not, highlight the related row.

Phase 6: Implement the above phase (1-5) operations unless the requirement is met with all values in the table.

\subsection{Algorithm of the Proposed Method}

An algorithm has been developed according to the six points listed above and presented in Table 2 . In reality, this algorithm serves as the primary workflow or computational instruction for completing the computation

Table 2. Algorithm for calculation of the total minimum cost in transportation problem






\subsection{Computational code of the Proposed Method}

The coding can be easily understood with the aid of this algorithm. The required computational code (program code) was generated using the Python programming language based on the above algorithm, as shown in Table 3.

Table 3. Coding for our newly proposed method

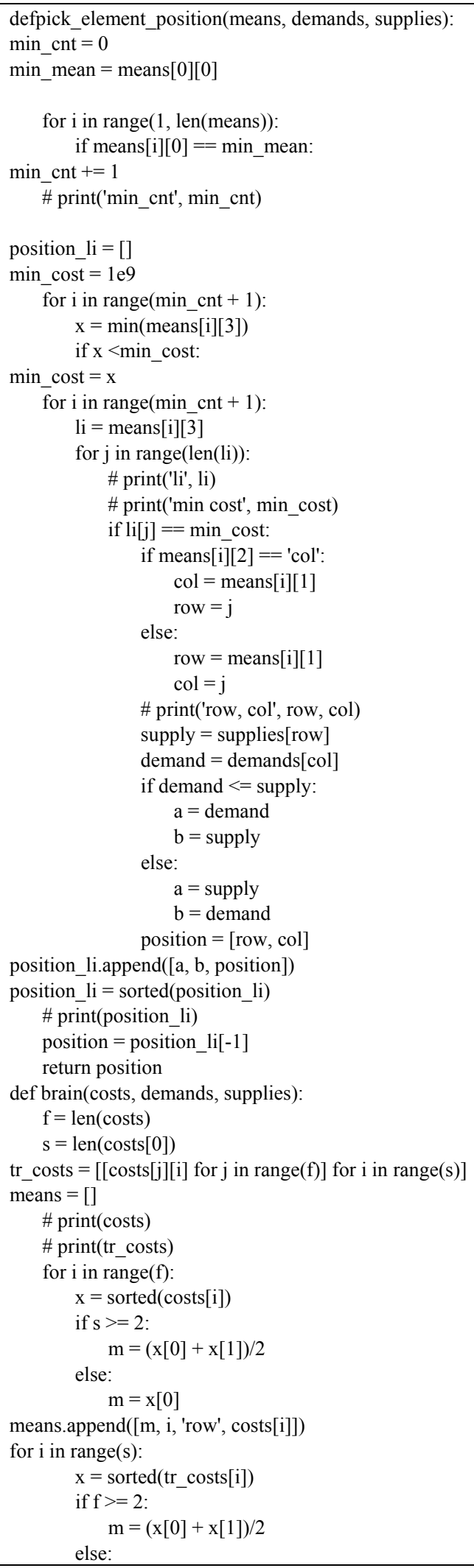




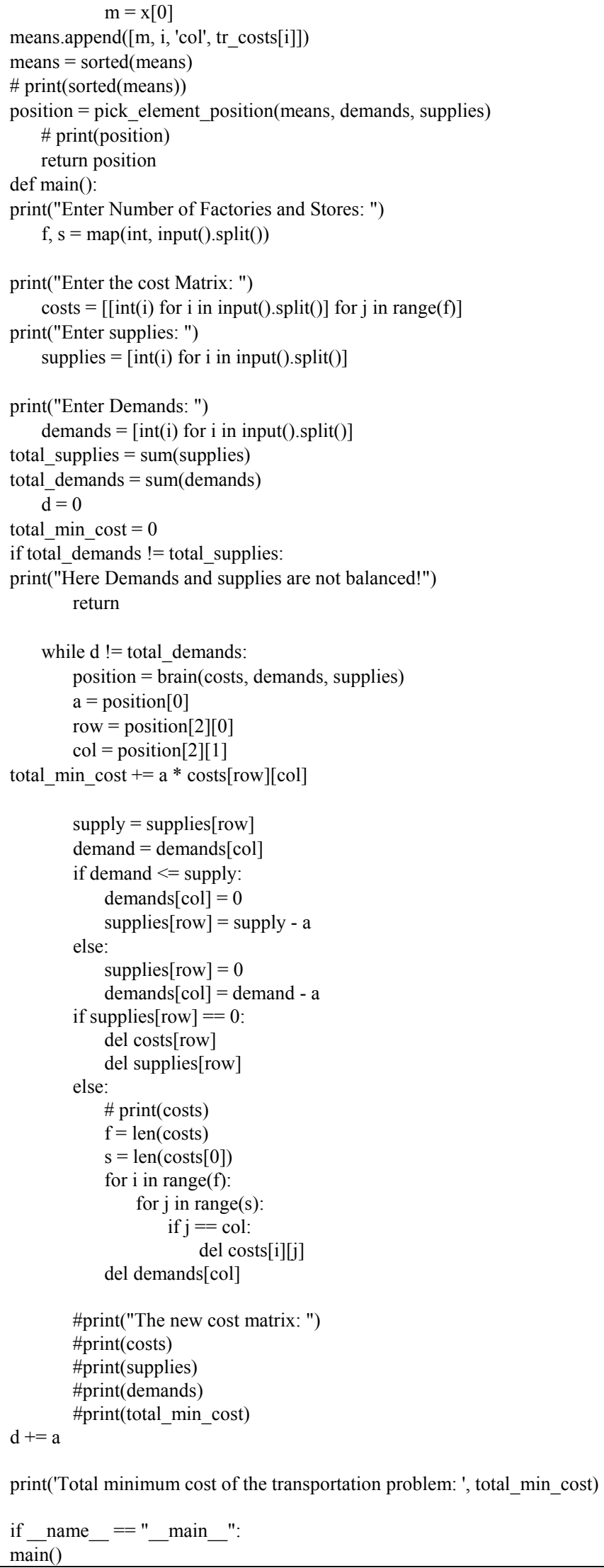




\subsection{Data Collection Procedure}

To examine the effectiveness of our proposed approach in solving the transportation problem, a well-established foodstuff producing/manufacturing company "Globe Food and Beverage Bangladesh (GFBB) limited" has been selected randomly. Necessary data were collected from the management/concerned division. The company produces a range of goods from several factories located in different places. Specifically, it produced more than 20 different foodstuffs from 8 different factories located in several places. After production, packaging, and management clearances, the products are delivered to the consumers/dealers in various places throughout the country according to the demand. It is impossible to accomplish such a huge job without an algorithm or a proper computational scheme, especially when the minimization of distribution cost is of prime concern where there are multiple sources and multiple destinations. A summary of the collected data is presented in the following tables.

\subsection{Implementation}

\section{Case 1:}

The company "Globe Food and Beverage Bangladesh ltd." produces a soft drink named "mangolee" which has to deliver to shops $\mathrm{p}, \mathrm{q}, \mathrm{r}, \mathrm{s}, \mathrm{t}$ via several suppliers $\mathrm{x}, \mathrm{y}$, and $\mathrm{z}$. The stock of each supplier and the demand of each shop are known in Table 4. We seek a viable option for minimum distribution cost by using the proposed method in the transportation problem given in Table 4.

Table 4. Production and distribution data for soft drinks 'mangole' (Scenario 1)

\begin{tabular}{|c|c|c|c|c|c|c|}
\hline $\begin{array}{c}\text { Destination } \\
\text { Source }\end{array}$ & $\mathbf{p}$ & $\mathbf{q}$ & $\mathbf{r}$ & $\mathbf{s}$ & $\mathbf{t}$ & Distribution \\
\hline $\mathrm{x}$ & 55 & 30 & 40 & 50 & 50 & 40 \\
\hline $\mathrm{y}$ & 35 & 30 & 100 & 45 & 60 & 20 \\
\hline $\mathrm{z}$ & 40 & 60 & 95 & 35 & 30 & 40 \\
\hline Required & 25 & 10 & 20 & 30 & 15 & 100 \\
\hline
\end{tabular}

\section{Solution:}

\section{Stage 1:}

Table 5 shows the computed mean number of the smallest two expenses for every column \& row.

\section{Stage 2:}

Table 6 shows that 30 is the lowest mean value, thus the $2^{\text {nd }}$ column was chosen, and in that scenario, the lowest spending amount is 30.Two lower expenses have been completed subsequently, each was picked arbitrarily and in that situation 10 was allocated and the second column was rounded off. The lowest price was picked up in the $1^{\text {st }}$ row, finished the work of $2^{\text {nd }}$ column by rounding off, and the mean figure was calculated among the smallest two prices for the left columns \&rows.

Table 5. Illustration-1, Iteration-1

\begin{tabular}{|c|c|c|c|c|c|c|c|}
\hline $\begin{array}{c}\text { Destination } \\
\text { Source }\end{array}$ & $\mathbf{p}$ & $\mathbf{q}$ & $\mathbf{r}$ & $\mathbf{s}$ & $\mathbf{t}$ & Delivering & $\begin{array}{c}\text { Mean statistic of } \\
\text { minimum two expenses }\end{array}$ \\
\hline $\mathrm{x}$ & 55 & 30 & 40 & 50 & 50 & 40 & 35 \\
\hline $\mathrm{y}$ & 35 & 30 & 100 & 45 & 60 & 20 & 32.5 \\
\hline $\mathrm{z}$ & 40 & 60 & 95 & 35 & 30 & 40 & 32.5 \\
\hline Request for & 25 & 10 & 20 & 30 & 15 & 100 & \\
\hline $\begin{array}{c}\text { Mean of least } \\
\text { two costs }\end{array}$ & 37.5 & 30 & 67.5 & 40 & 40 & & \\
\hline
\end{tabular}

Table 6. Illustration 1, Iteration 2

\begin{tabular}{|c|c|c|c|c|c|c|c|}
\hline $\begin{array}{c}\text { Destination } \\
\text { Source }\end{array}$ & $\mathbf{p}$ & $\mathbf{q}$ & $\mathbf{r}$ & $\mathbf{s}$ & $\mathbf{t}$ & Distribution & $\begin{array}{c}\text { Mean statistic of } \\
\text { minimum two expenses }\end{array}$ \\
\hline $\mathrm{x}$ & 55 & $30 \mathbf{1 0}$ & 40 & 50 & 50 & $40 / 30$ & 45 \\
\hline $\mathrm{y}$ & 35 & 30 & 100 & 45 & 60 & 20 & 40 \\
\hline $\mathrm{z}$ & 40 & 60 & 95 & 35 & 30 & 40 & 32.5 \\
\hline Need & 25 & $10 / 0$ & 20 & 30 & 15 & 100 & \\
\hline $\begin{array}{c}\text { Mean of least } \\
\text { two costs }\end{array}$ & 37.5 & & 67.5 & 40 & 40 & & \\
\hline
\end{tabular}




\section{Stage 3:}

Table 7 shows that the 3 rd row was included the smallest mean statistic, therefore, picked up the $3{ }^{\text {rd }}$ line, and taken the lowest amount of 30 and position 15 within the frame. After the need was satisfied, round off the fifth column. The mean figure was computed among the smallest two prices for the left columns \&rows.

Table 7. Illustration 1, Iteration 3

\begin{tabular}{|c|c|c|c|c|c|c|c|}
\hline $\begin{array}{c}\text { Destination } \\
\text { Source }\end{array}$ & $\mathbf{p}$ & $\mathbf{q}$ & $\mathbf{r}$ & $\mathbf{s}$ & $\mathbf{t}$ & Distribution & $\begin{array}{c}\text { Mean statistic of } \\
\text { minimum two expenses }\end{array}$ \\
\hline $\mathrm{x}$ & 55 & 3010 & 40 & 50 & 50 & $40 / 30$ & 45 \\
\hline $\mathrm{y}$ & 35 & 30 & 100 & 45 & 60 & 20 & 40 \\
\hline z & 40 & 60 & 95 & 35 & 3015 & $40 / 25$ & 40 \\
\hline Required & 25 & $10 / 0$ & 20 & 30 & $15 / 0$ & 100 & \\
\hline $\begin{array}{l}\text { Mean of least } \\
\text { two costs }\end{array}$ & 37.5 & & 67.5 & 40 & & & \\
\hline
\end{tabular}

\section{Stage 4:}

Currently (Table 8), the smallest mean statistic was included in the $1^{\text {st }}$ column, therefore, the $1^{\text {st }}$ column was picked up, the lowest amount of 35 was taken and placed 20 inside the cell 35 and the $2^{\text {nd }}$ row was rounded off. The mean figure among the smallest two prices for the left columns \& rows was computed.

Table 8. Illustration 1, Iteration 4

\begin{tabular}{|c|c|c|c|c|c|c|c|}
\hline $\begin{array}{c}\text { Destination } \\
\text { Source }\end{array}$ & $\mathbf{p}$ & $\mathbf{q}$ & $\mathbf{r}$ & $\mathbf{s}$ & t & Delivering & $\begin{array}{c}\text { Mean statistic of } \\
\text { minimum two expenses }\end{array}$ \\
\hline $\mathrm{x}$ & 55 & 3010 & 40 & 50 & 50 & $40 / 30$ & 45 \\
\hline $\mathrm{y}$ & $3 5 \longdiv { 2 0 }$ & 30 & 100 & 45 & 60 & $20 / 0$ & \\
\hline $\mathrm{z}$ & 40 & 60 & 95 & 35 & 3015 & $40 / 25$ & 40 \\
\hline Request for & $25 / 5$ & $10 / 0$ & 20 & 30 & $15 / 0$ & 100 & \\
\hline $\begin{array}{l}\text { Mean of least } \\
\text { two costs }\end{array}$ & 47.5 & & 67.5 & 40 & & & \\
\hline
\end{tabular}

\section{Stage 5}

Currently, the third row was included in the smallest mean figure (Table 9). Therefore, the third row was picked up, and the lowest amount of 35 was taken, 25 were placed inside the cell of 35 and the $3^{\text {rd }}$ row was rounded off.

Table 9. Illustration 1, Iteration 5

\begin{tabular}{|c|c|c|c|c|c|c|c|}
\hline $\begin{array}{c}\text { Destination } \\
\text { Source }\end{array}$ & $\mathbf{p}$ & $\mathbf{q}$ & $\mathbf{r}$ & $\mathbf{S}$ & $\mathbf{t}$ & Distribution & $\begin{array}{c}\text { Mean statistic of } \\
\text { minimum two expenses }\end{array}$ \\
\hline $\mathrm{x}$ & 55 & $30 \sqrt{\mathbf{1 0}}$ & 40 & 50 & 50 & $40 / 30$ & 45 \\
\hline $\mathrm{y}$ & $35 \mathbf{2 0}$ & 30 & 100 & 45 & 60 & $20 / 0$ & \\
\hline $\mathrm{z}$ & 40 & 60 & 95 & $35 \sqrt{\mathbf{2 5}}$ & $30 \sqrt{\mathbf{1 5}}$ & $40 / 25 / 0$ & \\
\hline Need & $25 / 5$ & $10 / 0$ & 20 & $30 / 5$ & $15 / 0$ & 100 & \\
\hline $\begin{array}{c}\text { Mean of least } \\
\text { two costs }\end{array}$ & 55 & & 40 & 50 & & & \\
\hline
\end{tabular}

\section{Stage 6:}

Only the $1^{\text {st }}$ row exists now (Table 10$)$. Hence $1^{\text {st }}, 3^{\text {rd }}$, and $4^{\text {th }}$ chambers of the $1^{\text {st }}$ row are furnishedwith 20,5 , and 5 in that order.

Table 10. Illustration 1, Iteration 6

\begin{tabular}{|c|c|c|c|c|c|c|c|}
\hline $\begin{array}{c}\text { Destination } \\
\text { Source }\end{array}$ & $\mathbf{p}$ & $\mathbf{q}$ & $\mathbf{r}$ & $\mathbf{s}$ & $\mathbf{t}$ & Distribution & $\begin{array}{c}\text { Mean statistic of } \\
\text { minimum two expenses }\end{array}$ \\
\hline $\mathrm{x}$ & $55 \mathbf{5}$ & $30 \sqrt[\mathbf{1 0}]{ }$ & $40 \mathbf{2 0}$ & $50-\mathbf{5}$ & 50 & $40 / 30 / 10 / 5 / 0$ & \\
\hline $\mathrm{y}$ & $35 \mathbf{2 0}$ & 30 & 100 & 45 & 60 & $20 / 0$ & \\
\hline $\mathrm{z}$ & 40 & 60 & 95 & 3525 & $30 / \mathbf{1 5}$ & $40 / 25 / 0$ & \\
\hline Required & $25 / 5 / 0$ & $10 / 0$ & $20 / 0$ & $30 / 5 / 0$ & $15 / 0$ & 100 & \\
\hline $\begin{array}{c}\text { Mean of least } \\
\text { two costs }\end{array}$ & & & & & & \\
\hline
\end{tabular}


Overall expenses from table 10 can be calculated as follows:

$($ i. $30 \times 10)+($ ii. $30 \times 15)+($ iii. $35 \times 25)+($ iv. $35 \times 20)+($ v. $40 \times 20)+($ vi. $50 \times 5)+($ vii. $55 \times 5)=\mathbf{3 , 6 5 0}$ units

The solution to this problem (Table 10), based on the other methods available in the literature are as follows:

$\begin{array}{rlr}\text { i. } & \text { By Least Cost Method } & 3650 \\ \text { ii. } & \text { NWC Method } & 5325 \\ \text { iii. } & \text { Column Minima Method } & 3700 \\ \text { iv. } & \text { Vogel Approximation Model } 3650 \\ \text { v. } & \text { Row Minima Method } & 3650\end{array}$

The aforementioned calculation shows that our proposed approach can provide one of the minimum costs compared to the other methods available in the literature.

\section{Case2:}

Another product of "Globe Food and Beverage Bangladesh ltd." is "Uro Cola" which is produced and supplied from three outlets s, t, $u$ to three super shops p, q, r. The information is given in Table 11, while Tables 12-14 contain the illustrations and iteration to solve the problem described in Table 11.

Table 11. Supply and distribution scenario for beverage 'Uro Cola'

\begin{tabular}{|c|c|c|c|c|}
\hline $\begin{array}{c}\text { Destination } \\
\text { Source }\end{array}$ & s & t & u & Distribution \\
\hline $\mathrm{p}$ & 6 & 4 & 50 & 7 \\
\hline $\mathrm{q}$ & 3 & 8 & 2 & 30 \\
\hline $\mathrm{r}$ & 4 & 4 & 35 & 150 \\
\hline Request for & 20 & 95 & 35 \\
\hline
\end{tabular}

\section{Answer:}

Table 12. Illustration 2, Iteration 1

\begin{tabular}{|c|c|c|c|c|c|}
\hline $\begin{array}{c}\text { Destination } \\
\text { Source }\end{array}$ & s & t & u & $\begin{array}{c}\text { Mean statistic of } \\
\text { Distribution }\end{array}$ \\
\hline $\mathrm{p}$ & 6 & 4 & 1 & 50 & 40 \\
\hline $\mathrm{q}$ & 3 & 8 & 7 & 2.5 & 50 \\
\hline $\mathrm{r}$ & 4 & 4 & 35 & 150 & 3 \\
\hline Need & 20 & 95 & 1.5 & & \\
\hline $\begin{array}{c}\text { Mean of least two } \\
\text { costs }\end{array}$ & 3.5 & 4 & & \\
\hline
\end{tabular}

Table 13. Illustration 2, Iteration 2

\begin{tabular}{|c|c|c|c|c|c|}
\hline $\begin{array}{c}\text { Destination } \\
\text { Source }\end{array}$ & s & t & u & Distribution & $\begin{array}{c}\text { Mean statistic of minimum two } \\
\text { expenses }\end{array}$ \\
\hline $\mathrm{p}$ & 6 & 4 & $1 \mathbf{3 5}$ & 50 & 5 \\
\hline $\mathrm{q}$ & 3 & 8 & 7 & 40 & 50 \\
\hline $\mathrm{r}$ & 4 & 4 & 2 & 150 & 4 \\
\hline Request for & 20 & 95 & 35 & & \\
\hline Mean of least two cost & 3.5 & 4 & & & \\
\hline
\end{tabular}

Table 14. Illustration 2, Iteration 3

\begin{tabular}{|c|c|c|c|c|c|}
\hline $\begin{array}{c}\text { Destination } \\
\text { Source }\end{array}$ & s & $\mathbf{t}$ & $\mathbf{u}$ & Distribution & $\begin{array}{c}\text { Mean statistic of minimum } \\
\text { two expenses }\end{array}$ \\
\hline $\mathrm{p}$ & 6 & 4 & $1 \mathbf{3 5}$ & $50 / 15$ & 4 \\
\hline $\mathrm{q}$ & $3 \mathbf{2 0}$ & 8 & 7 & $40 / 20$ & 60 \\
\hline $\mathrm{r}$ & 4 & 4 & 2 & 150 & 4 \\
\hline Need & $20 / 0$ & 95 & $35 / 0$ & & \\
\hline Mean of least two cost & & 4 & & & \\
\hline
\end{tabular}


Table 15. Illustration 2, Iteration 4

\begin{tabular}{|c|c|c|c|c|c|}
\hline $\begin{array}{c}\text { Destination } \\
\text { Source }\end{array}$ & $\mathbf{s}$ & $\mathbf{t}$ & $\mathbf{u}$ & Distribution & $\begin{array}{c}\text { Mean statistic of } \\
\text { minimum two expenses }\end{array}$ \\
\hline $\mathrm{p}$ & 6 & 415 & 135 & $50 / 15 / 0$ & \\
\hline q & 320 & 820 & 7 & $40 / 20 / 0$ & \\
\hline $\mathrm{r}$ & 4 & 460 & 2 & $60 / 0$ & \\
\hline Required & $20 / 0$ & $95 / 35 / 20 / 0$ & $35 / 0$ & 150 & \\
\hline Mean of least two cost & & & & & \\
\hline
\end{tabular}

Overall expenses from table 15 can be calculated as follows:

$($ i. $1 \times 35)+($ ii. $3 \times 20)+($ iii. $4 \times 60)+($ iv. $4 \times 15)+($ v. $8 \times 20)$ $=\mathbf{5 5 5}$ units

The solution to this issue, based on the following Methods:

i. By Least Cost Method 555

ii. NWC Method 730

iii. Column Minima Method 595

iv. Vogel Approximation Model 555

v. Row Minima Method 555

Based on the obtained results, our proposed approach offers an ideal feasible solution.

\section{Case3:}

Table 16 shows the unit costs of transporting a soft drink named "Uro Lemon" of the "Globe Food and Beverage Bangladesh ltd." from each of three factories $\mathrm{x}, \mathrm{y}, \mathrm{z}$ to each storehouse p, q, r, s, t. It also shows the stock of each factory and the demand for each storehouse. Complete information is given in Table 16 to find the cost-minimizing way using our proposed method:

Table 16. Supply and distribution scenario for beverage 'UroLemon'

\begin{tabular}{|c|c|c|c|c|c|c|}
\hline $\begin{array}{c}\text { Destination } \\
\text { Source }\end{array}$ & $\mathbf{p}$ & $\mathbf{q}$ & $\mathbf{r}$ & $\mathbf{s}$ & $\mathbf{t}$ & Distribution \\
\hline $\mathrm{x}$ & 4 & 1 & 3 & 4 & 4 & 60 \\
\hline $\mathrm{y}$ & 2 & 3 & 2 & 2 & 3 & 35 \\
\hline $\mathrm{z}$ & 3 & 5 & 2 & 4 & 4 & 40 \\
\hline Request for & 22 & 45 & 20 & 18 & 30 & 135 \\
\hline
\end{tabular}

Overall expenses by the suggested method from Table 16 can be calculated as follows:

$$
\text { (i. } \begin{aligned}
1 \times 45)+ & (\text { ii. } 2 \times 22)+(\text { iii. } 2 \times 20)+(\text { iv. } 2 \times 13)+(\text { v. } 4 \times 20) \\
& +(\text { vi. } 4 \times 10)+(\text { vii. } 4 \times 5)=\mathbf{2 9 5} \text { units }
\end{aligned}
$$

The solution to this issue, based on the following Methods:

$\begin{array}{rlr}\text { i. } & \text { Row Minima Method } & 310 \\ \text { ii. } & \text { NWC Method } & 363 \\ \text { iii. } & \text { Least Cost Method } & 295 \\ \text { iv. } & \text { Vogel's Approximation Method } & 305 \\ \text { v. } & \text { Column Minima Method } & 295\end{array}$

Obtained results show that our proposed approach offers an ideal, workable alternative that is quite suitable and favourable compared with the other existing methods.

\section{Results and Discussion}

In this study, we developed a computational program based on the typical concept of the transport problem. Based on our new program we tested different scenarios for practical applications. For example, we examined three cases and showed how our proposed method works in three cases. In the case of the tested scenario, our proposed model produced either a better result (in some cases) or showed a similar result (some other cases) compared to the existing methods.

In the case of scenario1, our proposed method gave better results than the two existing methods like NWC and $\mathrm{CMM}$, and similar results to the other three existing methods like VAM, LCM, and RMM. In scenario 2, our method gave a better result than two existing methods NWC and CMM, which gave a similar result as VAM, LCM, and RMM. In scenario 3, our method gave a better result than the existing three methods VAM, NW, and RMM, and gave similar results as LCM, CMM. The results revealed that our proposed method offers better solutions in all studied scenarios than the other existing methods. The output of the above scenarios also shows that our proposed method produces either the same or better results than Vogel's method. Although VAM has shown relatively good results, not in all cases in the practical view or the practical case. More specifically, for all of the three studied cases, Vogel's is not showing the least data but our method is producing the least data in all cases, in addition to LCM. This indicates that our proposed approach is based on a more sophisticated algorithm and computational capabilities, resulting in a superior result.

The tested scenario under this study revealed that NWC is simple to comprehend; nevertheless, this approach cannot offer an ideal outcome relative to our proposed one. On the other side, VAM offers the best potential result, but the approach is difficult and lengthy compared to our proposed method. Thus, the new approach offers the best outcome than the NWC Law, therefore offering an ideal or close-best comparison to the VAM. Due to advancements in computer programming, the proposed method appears to be very easy to implement and requires a small amount of 
computing time as compared to other methods in the literature. Also, the viable approach reached by the suggested alternative system is equivalent to an optimum approach relative to other traditional conventional approaches. While many steps need to be taken to solve the transportation problem using Vogel's or another existing method, our newly proposed method requires only a few steps to solve the problem. Analyzing the three cases mentioned above, we found the best solution by using our newly proposed method compared to the other five methods.

Reviewing cases 1 and 3 in Section 3.4, we see that the difference between the costs of case 1 is a little more than the cost of case 3 . So, we got better results in case 3 than in case 1 .

\section{Conclusions}

To date, several possible approaches have been suggested by the researcher to find an appropriate methodology for an efficient solution to the transport problem. Here, we presented a new/alternative approach to obtain an easy, workable solution to the transport problem. Some detailed empirical illustrations have been provided for a more reliable explanation of the method suggested. Since our proposed method is simpler than Vogel's and another existing method, takes rapid time to use, easier to understand, thus it may be easily applicable in solving the real-world problem. Since it provides better or the same optimal result compared to Vogel's and other existing methods, so we can conclude that our newly proposed method is much more effective than existing methods. Owing to the generalization of the recently created method, it would be really useful for policymakers related to service and delivery discipline. It is anticipated that the developed program will be suitable to be used effectively for solving the large-scale transportation problem.

There should be more research on issues like shipping cargo goods from one country to another on a larger scale in the future; which will be used to provide more effective approaches to overcome specific problems and finding appropriate solutions to transportation problems.

\section{Declarations}

ACKNOWLEDGEMENTS: We'd like to thank Almighty Allah for His security during this research project, as well as those who offered different suggestions to help make it a success.

STATEMENT OF ETHICAL APPROVAL: In compliance with local legislation and national guidelines, no ethical approval was needed for this report.

CONFLICT OF INTEREST AND ETHICAL STANDARDS: There were no commercial or financial partnerships that could be described as a possible conflict of interest during the study.

\section{REFERENCES}

[1] T. Poggio, Q. Liao, "Theory II: Deep learning and optimization", Bulletin of the Polish Academy of Sciences: Technical Sciences. Vol. 66, no 6, pp. 775-787, 2018

[2] MM Ahmed, AR Khan, MS Uddin, F Ahmed "A New Approach to Solve Transportation Problems," Open J Optim, vol. 5, no. 1, pp. 22-30, 2016, doi:10.4236/ojop.2016.51003

[3] A. L. Kok, E. W. Hans and J. M. J. Schutten, "Optimizing departure times in vehicle routes," European Journal of Operational Research, vol. 210, no. 3, pp. 579-587, 2011. http://dx.doi.org/10.1016/j.ejor.2010.10.017

[4] K. Kowalski, "On the structure of the fixed charge transportation problem," International Journal of Mathematical Education in Science and Technology, vol. 36, no. 8, pp. 879-888, 2005, DOI: $10.1080 / 00207390500137837$

[5] O Díaz-Parra, JA Ruiz-Vanoye, B Bernábe Loranca, A Fuentes-Penna , RA Barrera-Cámara , "A survey of transportation problems," J Appl Math, vol. 2014, no 3, pp. 1-17, 2014, https://doi.org/10.1155/2014/848129

[6] P Ji and K.F. Ghu, "A dual-matrix approach to the transportation problem," Asia-Pacific Journal of Operations Research, vol. 19, no. 1, pp. 35-45, 2002. https://research.polyu.edu.hk/en/publications/a-dual-matrix -approach-to-the-transportation-problem

[7] M Hanif, FS Rafi . A New Method for Optimal Solutions of Transportation Problems in LPP. J Math Res. vol. 10, no. 5, pp.60-75, 2018. doi:10.5539/jmr.v10n5p60

[8] I Nikolić , "Total time minimizing transportation problem," Yugosl J Oper Res, vol. 17, no 1, pp. 125-133, 2007. doi:10.2298/YJOR0701125N

[9] Z.A.M.S. Juman and N.G.S.A. Nawarathne, "An efficient alternative approach to solve a transportation problem," Ceylon J Sci., vol. 48, no. 1, pp. 19-29, 2019, DOI: http://doi.org/10.4038/cjs.v48i1.7584

[10] A. Veena and K. Krzysztof, "An alternative solution algorithm for certain transportation problems," International Journal of Mathematical Education in Science and Technology, vol. 30, no. 5, pp. 719-728, 1999, DOI: $10.1080 / 002073999287716$

[11] UK Das , A Babu, A Helal, S. Uddin, "Logical Development of Vogel ' $\mathrm{s}$ Approximation Method (LD-VAM )," An Approach To Find Basic Feasible Solution of Transportation Problem, Int J SciTechnol Res, vol. 3, no. 2, pp. 42-48, 2014 https://www.ijstr.org/paper-references.php?ref=IJSTR-021 4-8173

[12] ID Ezekiel, "Modified Vogel Approximation Method For Balanced Transportation Models Towards Optimal Option Settings," Int J CivEngTechnol, vol. 9, no. 12, pp. 358-366, 2018. 
http://www.iaeme.com/IJCIET/issues.asp?JType=IJCIET \&VType $=9 \&$ IType $=12$

[13] N. Balakrishnan, "Modified Vogel's Approximation Method for the Unbalanced Transportation Problem," Appl Math Lett, vol 3, no. 2, pp. 9-11, 1990, https://core.ac.uk/download/pdf/82047862.pdf

[14] AS Soomro, M Junaid, GA Tularam, "Modified Vogel's Approximation Method For Solving, "Mathematical theory and Modeling", vol. 5, no. 4, pp. 32-42, 2015.https://www.iiste.org/Journals/index.php/MTM/articl e/view/21567

[15] AE Samuel, M Venkatachalapathy, "Modified Vogel's Approximation Method for Fuzzy Transportation Problems," Appl Math Sci., vol. 5, no. 28, pp. 1367-1372, 2011.http:/www.m-hikari.com/ams/ams-2011/ams-25-282011/samuelAMS25-28-2011.pdf

[16] J Pratihar, R Kumar, S.A. Edalatpanah,. "Modified Vogel's approximation method for transportation problem under uncertain environment," Complex Intell. Syst. Vol. 7, pp. 29-40, 2021. https://doi.org/10.1007/s40747-020-00153-4

[17] S. Akpan, T. Ugbe, J. Usen, O. Ajah, "A Modified Vogel Approximation Method for Solving Balanced Transportation Problems, “ Am Sci Res J EngTechnol Sci., vol. 14, no. 3, pp. 289-302, 2015. https://asrjetsjournal.org/index.php/American_Scientific_J ournal/article/view/1074/643

[18] A.N.M. Rezaul Karim, "An efficient alternative approach to solve an assignment problem, J. Math. Comput. Sci, vol. 11, no 4, pp. 4810-4840, 2021.

https://doi.org/10.28919/jmcs/5695

[19] R Boadh, R Singh, YK Rajoria, “A Comparative Analysis for the Solution of Transportation Model by Various Methods," J Xi' an UnivArchit Technol., vol. XII, no. VI, pp. 825-832, 2020. doi:10.37896/JXAT12.06/1980 